University of South Carolina

Scholar Commons

$11-2004$

\title{
Physical Activity Among Children Attending Preschools
}

Russell R. Pate

University of South Carolina - Columbia, rpate@mailbox.sc.edu

Karin A. Pfeiffer

Stewart G. Trost

Paula Ziegler

Marsha Dowda

Follow this and additional works at: https://scholarcommons.sc.edu/

sph_physical_activity_public_health_facpub

Part of the Exercise Science Commons

\section{Publication Info}

Published in Pediatrics, Volume 114, 2004, pages 1258-1263.

(C) 2004 by the American Academy of Pediatrics.

This Article is brought to you by the Physical Activity and Public Health at Scholar Commons. It has been accepted for inclusion in Faculty Publications by an authorized administrator of Scholar Commons. For more information, please contact digres@mailbox.sc.edu. 


\title{
Physical Activity Among Children Attending Preschools
}

\author{
Russell R. Pate, PhD*; Karin A. Pfeiffer, PhD*; Stewart G. Trost, PhDł; Paula Ziegler, PhD, RD§; and \\ Marsha Dowda, DrPH*
}

\begin{abstract}
Objectives. Obesity rates are increasing among children of all ages, and reduced physical activity is a likely contributor to this trend. Little is known about the physical activity behavior of preschool-aged children or about the influence of preschool attendance on physical activity. The purpose of this study was to describe the physical activity levels of children while they attend preschools, to identify the demographic factors that might be associated with physical activity among those children, and to determine the extent to which children's physical activity varies among preschools.

Methods. A total of 281 children from 9 preschools wore an Actigraph (Fort Walton Beach, FL) accelerometer for an average of 4.4 hours per day for an average of 6.6 days. Each child's height and weight were measured, and parents of participating children provided demographic and education data.

Results. The preschool that a child attended was a significant predictor of vigorous physical activity (VPA) and moderate-to-vigorous physical activity (MVPA). Boys participated in significantly more MVPA and VPA than did girls, and black children participated in more VPA than did white children. Age was not a significant predictor of MVPA or VPA.

Conclusions. Children's physical activity levels were highly variable among preschools, which suggests that preschool policies and practices have an important influence on the overall activity levels of the children the preschools serve. Pediatrics 2004;114:1258-1263; children, preschool, child day care centers, physical activity, accelerometer.
\end{abstract}

ABBREVIATIONS. BMI, body mass index; MVPA, moderate-tovigorous physical activity; VPA, vigorous physical activity; MET, metabolic equivalent.

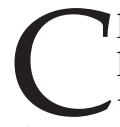
hildhood obesity rates in the United States have skyrocketed in recent decades. ${ }^{1,2}$ This trend is evident among preschool-aged children as well as among older children and adolescents. ${ }^{2-4}$ The prevalence of overweight among 4- and 5-year-old children increased from 5.8\% in 1971-1974 to $>10 \%$ in $1988-1994 .{ }^{3}$ Among all preschool-aged children (ages 2-5), 10.1\% are overweight and an

From the *Department of Exercise Science, Arnold School of Public Health, University of South Carolina, Columbia, South Carolina; łDepartment of Kinesiology and Community Health Institute, Kansas State University, Manhattan, Kansas; and §Gerber Products Company, Parsippany, NJ. Accepted for publication May 6, 2004.

doi:10.1542/peds.2003-1088-L

Address correspondence to Russell R. Pate, PhD, Devine Street Research Center, 730 Devine St, Columbia, SC 29208. E-mail: rpate@gwm.sc.edu PEDIATRICS (ISSN 0031 4005). Copyright (C) 2004 by the American Academy of Pediatrics. additional $10.7 \%$ are at risk for becoming overweight. ${ }^{4}$ Obesity is associated with adverse health outcomes among both children and adults, ${ }^{5-7}$ and overweight status tends to track from childhood into adulthood. ${ }^{8}$ Because treatment of obesity is unsuccessful frequently, primary prevention of obesity has become an important public health priority. ${ }^{9}$ Many experts have recommended that public health initiatives to prevent obesity should begin with our youngest children. ${ }^{9}$

It seems certain that decreased physical activity is contributing to the increase in childhood overweight and obesity.9,10 Public health authorities have issued recommendations for promotion of physical activity among children and adolescents, ${ }^{11}$ and the National Association for Sport and Physical Education recently released physical activity guidelines for young children attending preschools. ${ }^{12}$ Although $\sim 56 \%$ of 3- to 5-year-old children in the United States attend preschools, ${ }^{13}$ the scientific literature includes few studies of physical activity levels among preschoolaged children, and very little is known about the activity levels of children while they attend preschools.

If policies are to be designed and disseminated for the purpose of increasing physical activity among preschool-aged children, then those policies should be developed on the basis of careful studies of the physical activity levels of children in that age range. Specifically, it seems important that data be available to document the activity levels of children while they attend preschools, because public health policies could target the practices of those schools. In that context, it is also important to know the extent to which children's activity levels vary among preschools. Therefore, the purposes of this study were 1) to describe the physical activity levels of children attending preschools, 2) to identify the demographic factors that might be associated with physical activity among those children, and 3) to determine the extent to which children's physical activity varies among preschools.

\section{METHODS}

\section{Sample}

Subjects for this study were recruited from 9 preschools in the Columbia, South Carolina, metropolitan area. Before selection, all preschools with an enrollment of $\geq 60$ children were identified and classified as privately operated (private), church-based (church), or predominantly government-funded (Head Start). From each of these 3 groups, 3 preschools were randomly selected. If a preschool refused to participate or could not provide a sufficient 
number of participants, then a replacement preschool was randomly selected from the appropriate group.

Parents of all 3-, 4-, and 5-year-old children who attended the 9 preschools were invited to enroll their children in the study. Our goal was to recruit 30 children from each school. This goal was attained for 7 of the preschools, and the number of volunteers ranged from 22 to 30 (mean \pm SD: $27.4 \pm 3.1$ ). This represented recruitment rates of $28 \%, 44 \%$, and $45 \%$ of all children enrolled in the private, church, and Head Start preschools, respectively. All children whose parents provided informed consent $(N=281)$ participated in the study. After deletions for missing data on physical activity $(n=16)$, race/ethnicity $(n=13)$, and parent education $(n=5)$, the sample size was reduced to 247 child participants (132 girls and 115 boys). Fifty-three percent of the children in the study were female and $65 \%$ were black. The mean body mass index (BMI) was 16.1 (SD: 1.8). Additional descriptive statistics for the sample are presented in Table 1. Before participation in the study, written informed consent was obtained from each child's parent or guardian. The study was approved by the University of South Carolina Institutional Review Board.

\section{Assessment of Physical Activity}

Physical activity was quantified with the Actigraph (Fort Walton Beach, FL) uniaxial accelerometer (formerly known as the Computer Science and Applications 7164). Accelerometry has been shown to provide valid assessments of physical activity among preschool-aged children. ${ }^{14-16}$ After arrival at the preschool, participants were outfitted with a single Actigraph activity monitor. Monitors were attached to adjustable elastic belts and worn over the right hip. Because the 1-minute sampling interval typically used for accelerometry may mask the short intermittent bursts of activity characteristic of young children, a 15-second sampling interval was used. The number of days and the length of time per day that children wore the accelerometer varied according to the amount of time spent by the child at the preschool and the child's receptivity to wearing the monitor, which was very high for virtually all of the children. The number of monitoring days ranged from 1 to 11 days (mean \pm SD: $6.6 \pm 2.3$ days); the monitoring time for each day ranged from 0.4 to 7.8 hours (mean \pm SD: $4.4 \pm 1.3$ hours). Only participants who wore the accelerometer for $\geq 1$ hour on $\geq 3$ days were included in the analyses. The amount of monitoring did not differ significantly according to gender, age, parent education, or type of preschool; however, black children were monitored on significantly more days than white children (Table 1). Differences were also seen for mean hours per day of monitoring according to parent education level and type of preschool.

\section{Data Reduction}

Activity counts for each 15-second interval were uploaded to a Visual Basic data reduction program to determine total counts per hour of monitoring, number of intervals of light physical activity per hour, number of intervals of moderate-to-vigorous physical activity (MVPA) per hour, and number of intervals of vigorous physical activity (VPA) per hour. Age-specific count cutoffs corresponding to sedentary activity ( $\leq 1.4$ metabolic equivalents [METs]), light physical activity (1.5-2.9 METs), moderate physical activity (3-5.9 METs), MVPA ( $\geq 3$ METs), and VPA ( $\geq 6$ METs) were derived from the MET prediction equation developed by Sirard et al, ${ }^{16}$ ie, METs $=1.43+0.00399$ (counts) -0.14882 (age) $\left(r^{2}\right.$ $=0.79$ ). For an independent sample of 23 children 3 to 5 years of age, the correlations between intensity of physical activity observed with the Children's Activity Rating Scale ${ }^{17}$ and the number of VPA and MVPA counts per hour were 0.67 and 0.52 , respectively $(P<.05)$. Mean sedentary activity, light physical activity, MVPA, and VPA minutes per hour are reported for each demographic category and preschool in Table 2 .

\section{Child Weight Status}

Height and weight assessments were conducted in a private setting, with the children dressed in light clothing. Height was measured to the nearest $1.0 \mathrm{~cm}$ with a portable stadiometer. Weight was measured to the nearest $0.1 \mathrm{~kg}$ with high-precision electronic scales (Seca Corp, Birmingham, United Kingdom). BMI was calculated as body mass (in kilograms) divided by height (in meters) squared. Parents completed a brief questionnaire that assessed sociodemographic information.

\section{Statistical Analyses}

All statistical analyses were performed with SAS software (version 8.2; SAS Institute, Cary, NC). Differences in the physical activity variables among gender, age, race, and parent education groups were tested with one-way analysis of variance. To control for any clustering of physical activity within preschools, all analyses of variance were performed with PROC MIXED, ${ }^{18}$ with preschool included as a random effect. To delineate the contribution of preschool to the prediction of physical activity behavior, 2 multiple linear regression models were constructed. The first regression model included age, gender (male $=1$, female $=0$ ), race $(1=$ black, 0 = white), BMI, and parent education as independent variables. The second regression model contained the same independent variables as the first model but also included a block of 8 dummy variables representing the effect of each preschool. The

TABLE 1. Characteristics of Preschool-Aged Children Participating in the Study and Days and Hours of Accelerometry Data

\begin{tabular}{|c|c|c|c|c|}
\hline Characteristics & No. & Percent & Days, Mean (SD) & Hours per Day, Mean (SD) \\
\hline Total sample & 247 & & $6.9(1.8)$ & $4.6(1.3)$ \\
\hline \multicolumn{5}{|l|}{ Gender } \\
\hline Male & 115 & 46.6 & $6.9(1.7)$ & $4.5(1.3)$ \\
\hline \multirow[t]{2}{*}{ Female } & 132 & 53.4 & $6.9(1.8)$ & $4.7(1.3)$ \\
\hline \multirow{2}{*}{\multicolumn{5}{|c|}{ Age }} \\
\hline & & & & \\
\hline $3 y$ & 65 & 26.3 & $6.8(1.7)$ & $4.7(1.3)$ \\
\hline $4 \mathrm{y}$ & 113 & 45.7 & $7.1(1.8)$ & $4.6(1.3)$ \\
\hline \multirow[t]{2}{*}{$5 \mathrm{y}$} & 69 & 27.9 & $6.7(1.7)$ & $4.5(1.3)$ \\
\hline & & & $P=.27$ & $P=.74$ \\
\hline \multicolumn{5}{|l|}{ Race } \\
\hline Black & 161 & 65.2 & $7.2(1.8)$ & $4.6(1.4)$ \\
\hline \multirow[t]{2}{*}{ White } & 86 & 34.8 & $6.3(1.6)$ & $4.8(1.1)$ \\
\hline & & & $P<.001$ & $P=.17$ \\
\hline \multicolumn{5}{|l|}{ Parent education } \\
\hline High school & 63 & 25.5 & $7.3(1.5)$ & $4.0(1.2)$ \\
\hline Technical school/college & 144 & 58.3 & $6.8(1.8)$ & $4.9(1.2)$ \\
\hline \multirow[t]{2}{*}{ Graduate school } & 40 & 16.2 & $6.7(1.9)$ & $4.8(1.3)$ \\
\hline & & & $P=.17$ & $P<.001$ \\
\hline \multicolumn{5}{|l|}{ Type of preschool } \\
\hline Church & 90 & 36.4 & $6.9(2.1)$ & $5.6(0.7)$ \\
\hline Private & 81 & 32.8 & $7.2(1.6)$ & $5.0(1.1)$ \\
\hline \multirow[t]{2}{*}{ Head Start } & 76 & 30.8 & $6.6(1.5)$ & $3.2(0.4)$ \\
\hline & & & $P=.11$ & $P<.001$ \\
\hline
\end{tabular}


TABLE 2. Physical Activity Variables Among Preschool-Aged Children Categorized According to Gender, Age, Race, Parent Education, and Preschool

\begin{tabular}{|c|c|c|c|c|c|}
\hline & \multirow[t]{2}{*}{ No. } & \multicolumn{4}{|c|}{ Physical Activity, min/h } \\
\hline & & Sedentary & Light Activity & MVPA & VPA \\
\hline Total sample & 247 & $42.1(5.8)$ & $10.5(3.2)$ & $7.7(3.1)$ & $1.9(1.1)$ \\
\hline \multicolumn{6}{|l|}{ Gender } \\
\hline Male & 115 & $41.7(5.5)$ & $10.4(2.9)$ & $7.8(3.1)$ & $2.1(1.1)$ \\
\hline Female & 132 & $42.5(6.1)$ & $10.6(3.5)$ & $6.9(3.0)$ & $1.7(1.1)$ \\
\hline \multicolumn{6}{|l|}{ Age } \\
\hline $3 y$ & 65 & $39.6(6.1)$ & $12.4(3.5)$ & $8.0(3.2)$ & $1.9(1.1)$ \\
\hline $4 \mathrm{y}$ & 113 & $42.6(5.5)$ & $10.2(2.8)$ & $7.2(3.2)$ & $1.9(1.1)$ \\
\hline $5 \mathrm{y}$ & 69 & $43.7(5.3)$ & $9.3(2.8)$ & $7.0(2.8)$ & $1.9(1.1)$ \\
\hline \multicolumn{6}{|l|}{ Race } \\
\hline Black & 161 & $42.3(6.0)$ & $10.4(3.3)$ & $7.3(3.1)$ & $1.9(1.2)$ \\
\hline White & 86 & $41.9(5.6)$ & $10.7(3.0)$ & $7.4(3.1)$ & $1.8(1.0)$ \\
\hline \multicolumn{6}{|l|}{ Parent education } \\
\hline High school & 63 & $39.9(6.0)$ & $11.5(3.3)$ & $8.6(3.1)$ & $2.4(1.3)$ \\
\hline Technical school/college & 144 & $43.0(5.5)$ & $10.2(3.1)$ & $6.8(2.9)$ & $1.7(1.0)$ \\
\hline Graduate school & 40 & $42.5(6.0)$ & $10.3(3.1)$ & $7.3(3.3)$ & $1.9(1.1)$ \\
\hline \multicolumn{6}{|l|}{ Preschool } \\
\hline 1 & 30 & $46.2(4.2)$ & $8.8(2.7)$ & $5.0(1.8)$ & $1.2(0.6)$ \\
\hline 2 & 26 & $36.3(3.9)$ & $14.1(2.4)$ & $9.5(2.2)$ & $2.3(0.9)$ \\
\hline 3 & 29 & $45.1(4.2)$ & $9.0(2.4)$ & $5.9(2.1)$ & $1.6(0.7)$ \\
\hline 4 & 26 & $39.0(4.7)$ & $12.4(2.6)$ & $8.6(2.6)$ & $1.9(0.8)$ \\
\hline 5 & 29 & $37.9(3.6)$ & $11.9(1.9)$ & $10.2(2.5)$ & $3.4(1.4)$ \\
\hline 6 & 29 & $48.9(1.9)$ & $6.7(1.4)$ & $4.4(1.2)$ & $1.2(0.7)$ \\
\hline 7 & 22 & $44.3(4.5)$ & $9.9(2.4)$ & $5.8(2.3)$ & $1.4(0.7)$ \\
\hline 8 & 31 & $38.1(4.3)$ & $12.2(2.5)$ & $9.7(2.9)$ & $2.2(0.9)$ \\
\hline 9 & 25 & $43.4(5.1)$ & $9.7(2.8)$ & $6.8(2.7)$ & $1.9(1.2)$ \\
\hline
\end{tabular}

Values are mean (SD).

2-step regression analysis was performed for both MVPA and VPA. Statistical significance was set at an $\alpha$ level of .05.

\section{RESULTS}

Means and SEs for time spent in sedentary activity, light physical activity, MVPA, and VPA are shown in Table 3. Boys exhibited significantly greater participation in MVPA and VPA than did girls. No significant gender differences were observed for time spent in sedentary and light activity. Compared with 3-year-olds, 4- and 5-year-olds exhibited significantly more sedentary intervals and significantly fewer light activity intervals. No age-related differences were observed for MVPA or VPA. Black chil- dren tended to be more physically active than white children; however, only the difference for VPA reached statistical significance. No differences in activity levels were observed among parent education groups.

The results of the regression analyses are shown in Table 4. For MVPA, model 1, including gender, age, race/ethnicity, BMI, and parent education, accounted for $4.3 \%$ of the variance in physical activity. The addition of the preschool in model 2 dramatically improved the prediction of MVPA, accounting for an additional $43.3 \%$ of the variance. In model 1 , only gender and parent education emerged as signif-

TABLE 3. One-Way, Mixed-Model Analysis of Variance for Physical Activity Variables Among Preschool-Aged Children $(N=247)$, Controlling for Preschool

\begin{tabular}{|c|c|c|c|c|c|}
\hline \multirow[t]{2}{*}{ Characteristic } & \multirow[t]{2}{*}{ No. } & \multicolumn{4}{|c|}{ Physical Activity, min/h } \\
\hline & & Sedentary & Light & MVPA & VPA \\
\hline \multicolumn{6}{|l|}{ Gender } \\
\hline Male & 115 & $41.9(1.5)(P=.43)$ & $10.3(0.8)(P=.24)$ & $7.8(0.7)(P=.01)^{*}$ & $2.1(0.2)(P=.001)^{*}$ \\
\hline Female & 132 & $42.3(1.5)$ & $10.7(0.8)$ & $7.0(0.7)$ & $1.7(0.2)$ \\
\hline \multicolumn{6}{|l|}{ Age } \\
\hline $3 y$ & 65 & $40.1(1.5)(P<.001) \dagger$ & $12.2(0.8)(P<.001) \ddagger$ & $7.7(0.8)(P=.23)$ & $1.9(0.3)(P=.18)$ \\
\hline $4 \mathrm{y}$ & 113 & $42.6(1.5)$ & $10.3(0.7)$ & $7.1(0.7)$ & $1.8(0.2)$ \\
\hline $5 \mathrm{y}$ & 69 & $43.1(1.4)$ & $9.5(0.8)$ & $7.4(0.8)$ & $2.1(0.3)$ \\
\hline \multicolumn{6}{|l|}{ Race } \\
\hline Black & 161 & $41.7(1.5)(P=.27)$ & $10.6(0.8)(P=.93)$ & $7.6(0.8)(P=.06)$ & $2.0(0.2)(P=.04) \S$ \\
\hline White & 86 & $42.7(1.6)$ & $10.5(0.8)$ & $6.8(0.8)$ & $1.7(0.3)$ \\
\hline \multicolumn{6}{|l|}{ Parent education } \\
\hline High school & 63 & $41.3(1.5)(P=.32)$ & $10.7(0.8)(P=.77)$ & $7.9(0.8)(P=.10)$ & $2.1(0.2)(P=.17)$ \\
\hline Technical school/college & 144 & $42.3(1.5)$ & $10.5(0.8)$ & $7.2(0.7)$ & $1.8(0.2)$ \\
\hline Graduate school & 40 & $42.7(1.6)$ & $10.3(0.8)$ & $7.0(0.8)$ & $1.9(0.2)$ \\
\hline
\end{tabular}

Values are mean (SE).

* Male $>$ female.

† Means differ except for 4- and 5-year-old children.

$\ddagger$ All means differ.

$\S$ Black > white. 
TABLE 4. Results of Regression Analysis for Prediction of MVPA and VPA Among Preschool-Aged Children

\begin{tabular}{|c|c|c|c|c|c|c|c|c|}
\hline \multirow[t]{2}{*}{ Independent Variables } & \multicolumn{4}{|c|}{ MVPA } & \multicolumn{4}{|c|}{ VPA } \\
\hline & Standardized $\beta$ & $r^{2}$ & $F$ & $P$ & Standardized $\beta$ & $r^{2}$ & $F$ & $P$ \\
\hline \multicolumn{9}{|l|}{ Model 1} \\
\hline Intercept & 0 & & 36.54 & $<.001$ & 0 & & 27.92 & $<.001$ \\
\hline Parent education & -.14 & 0.023 & 4.86 & .029 & -.17 & 0.034 & 7.26 & .008 \\
\hline Gender $(0=$ female, $1=$ male $)$ & .13 & 0.019 & 4.32 & .039 & .14 & 0.021 & 5.30 & .022 \\
\hline Age & -.10 & 0.013 & 2.32 & .129 & .05 & 0.003 & 0.72 & .398 \\
\hline BMI & -.08 & 0.006 & 1.41 & .236 & -.19 & 0.035 & 8.47 & .004 \\
\hline Race $(0=$ white, $1=$ black $)$ & -.03 & 0.001 & 2.29 & .616 & .04 & 0.001 & 0.32 & .572 \\
\hline Total model & & 0.043 & 3.20 & .008 & & 0.074 & 4.95 & $<.001$ \\
\hline \multicolumn{9}{|l|}{ Model 2} \\
\hline Intercept & 0 & & 19.17 & $<.001$ & 0 & & 10.27 & .002 \\
\hline Parent education & -.10 & 0.005 & 2.90 & .090 & -.09 & 0.005 & 2.00 & .159 \\
\hline Gender $(0=$ female, $1=$ male $)$ & .02 & 0.017 & 5.76 & .017 & .15 & 0.039 & 8.10 & .005 \\
\hline Age & -.04 & 0.002 & 0.73 & .394 & .08 & 0.006 & 2.32 & .129 \\
\hline BMI & -.03 & 0.001 & 1.49 & .585 & -.11 & 0.012 & 4.50 & .035 \\
\hline Race $(0=$ white, $1=$ black $)$ & .15 & 0.006 & 4.40 & .037 & .17 & 0.009 & 4.89 & .028 \\
\hline Preschool & -.11 to .50 & $0.473^{*}$ & 25.89 & $<.001$ & -.10 to .49 & $0.344^{*}$ & 16.04 & $<.001$ \\
\hline Total model & & 0.476 & 18.18 & $<.001$ & & 0.383 & 12.73 & $<.001$ \\
\hline
\end{tabular}

* Sum of all preschools.

icant predictors of MVPA. In model 2, gender, race/ ethnicity, and preschool were significant predictors of MVPA.

For VPA, model 1, including gender, age, race/ ethnicity, BMI, and parent education, accounted for $7.4 \%$ of the variance. The addition of the preschool in model 2 markedly improved the prediction of VPA, accounting for an additional $30.9 \%$ of the variance. In model 1, gender, BMI, and parent education emerged as significant predictors of VPA. In model 2 , gender, race/ethnicity, BMI, and preschool were significant predictors.

\section{DISCUSSION}

A key finding of this study was that the preschool attended accounted for a substantial fraction of variance in child physical activity. This was true for both MVPA and VPA. Demographic factors such as gender and race were significantly associated with child physical activity, but the fractions of variance accounted for by these variables were small, compared with the fraction accounted for by the preschool. Mean minutes of MVPA, as measured objectively with accelerometry, varied from 4.4 to 10.2 minutes/ hour among the 9 preschools included in this study. These findings indicate that physical activity levels of children attending preschools vary greatly among schools and, importantly, the characteristics of the school have a much greater influence on a child's activity level while in the school than do the child's personal demographic characteristics. These findings, which are consistent with those of Finn et al, ${ }^{19}$ are important because they suggest that school policies and practices directed toward providing preschool-aged children with physical activity have the potential to influence greatly the overall physical activity levels of young children in the United States, $56 \%$ of whom attend formal preschools. ${ }^{13}$

Recently released guidelines suggested that preschool-aged children should accumulate at least 120 minutes of physical activity per day, one-half of that time in structured physical activity and the remainder in unstructured, free-play settings. ${ }^{12}$ The results of this study suggest that many preschool-aged children do not meet that standard. On average, the children in this study engaged in 7.7 minutes of MVPA per hour of preschool attendance $(\sim 13 \%$ of observed time). Therefore, a child who attends a preschool for 8 hours would engage in $\sim 1$ hour of MVPA. It seems unlikely that such a child would ordinarily engage in another 1 hour of physical activity outside the preschool setting. A factor that probably exerts a strong influence on physical activity in preschools is the time that children are allowed to play freely in settings that are conducive to physical activity, such as outdoor playgrounds or gymnasia. Previous studies with direct observational systems found that children engage in MVPA for $\sim 40 \%$ of the time they spend in outdoor recess, ${ }^{20}$ a much larger proportion of time than the $13 \%$ observed for the entire school day in this study. Clearly, one potentially effective strategy for providing children with adequate physical activity is to provide them with appropriate amounts of time in recess and other free-play settings.

During the course of the preschool day, boys participated in significantly greater amounts of MVPA and VPA than did girls, similar to findings of other studies. ${ }^{19,21-23}$ Currently, there is no definitive explanation regarding why girls participate in less physical activity than boys. The results of extensive metaanalyses suggest that sociocultural factors and not biological differences are primarily responsible for the gender gap in activity. ${ }^{24,25}$ It is possible that gender differences in playing styles may account for girls' lesser participation in physical activity. Observational studies of preschool-aged children have consistently demonstrated that boys play in larger groups and in more open settings, engage in more risk-taking behavior, and play rougher games involving greater amounts of body contact than do girls. ${ }^{26-28}$ Alternatively, girls may receive less encouragement from teachers and peers to engage in MVPA and VPA during the preschool day. However, previous studies examining physical activity behavior among preschool-aged children found no 
significant gender differences in prompts to be active. ${ }^{20,22}$ Whatever the underlying explanation for the observed gender difference, our observation that 3- to 5-year-old girls participated in significantly less physical activity than did boys while attending preschool strongly supports the recommendation that efforts to promote physical activity among girls should begin early in life. ${ }^{12,29}$ Additional studies are needed to identify the psychosocial and environmental factors that contribute to the gender difference in physical activity in the preschool setting.

Population surveys and descriptive epidemiologic studies have consistently observed children and adolescents from ethnic minorities to be less active than their white counterparts. ${ }^{30,31} \mathrm{Few}$ studies, however, have investigated the influence of race/ethnicity on physical activity behavior among preschool-aged children. In the study by McKenzie et al, ${ }^{22}$ Mexican American children were significantly less active and expended less energy than did their white counterparts in both settings (free play at home and during outdoor recess). Importantly, when home and recess activity levels were reexamined 2 years later in elementary school, Mexican American children continued to be less active than white children, which prompted the authors to suggest that racial/ethnic differences in physical activity might have their origins in early childhood. ${ }^{20}$ In contrast to those findings, Baranowski et $\mathrm{al}^{23}$ observed no significant differences in physical activity among white, black, and Mexican American children. In the present study, we compared the physical activity levels of white and black children during the preschool day. After controlling for the influence of preschool setting and other demographic variables, black children were found to be significantly more active than white children during the preschool day. This finding not only is in conflict with the results of previous preschool studies ${ }^{22,23}$ but also is inconsistent with the results of previous investigations in which black elementary school children were found to be less active than their white counterparts. ${ }^{32-34}$ Although the public health importance of our findings hinges on successful replication with larger, more representative samples of preschool-aged children, our observation of a significant racial/ethnic difference in physical activity during the preschool day raises several important questions for future research, including the following. Do racial/ethnic differences in physical activity levels during the preschool day generalize to other behavioral settings (eg, home)? What are the psychosocial and environmental factors that explain racial/ethnic differences in physical activity levels during the preschool day? What is the influence of race/ethnicity on the trajectory of physical activity behavior during the transition from preschool to elementary school?

The findings of this study suggest that physicians and other health care providers can help address the obesity epidemic by influencing the physical activity policies and practices of the preschools in their communities. Also, physicians who serve on licensing boards for preschools and those who serve as advisors to preschools in their communities can raise the issue of physical activity as a child health issue that preschools should address. In addition, health care providers can advise parents to consider physical activity services when they select a preschool for their child.

This study had limitations that should be noted. First, data were collected only during the preschool day; therefore, conclusions cannot be drawn regarding the impact of activity in the preschool on the overall physical activity of children. Second, the generalizability of the findings might be limited by the fact that all of the participating preschools were located in 1 metropolitan area. Also, data collection times were not uniform among demographic groups and types of schools. Black children were monitored for more days than were white children, and children attending Head Start preschools were monitored for fewer hours per day than were children attending other preschools. Although this factor might have influenced the findings, post hoc analyses indicated that the major conclusions of the study were not confounded by asymmetry in observation times among demographic and school groups. The asymmetry in observation times was associated with the inclusion of Head Start preschools, which in South Carolina enroll a disproportionately high percentage of black children and which operate for only $\sim 6$ hours per day. We replicated our core analyses after deleting data collected in Head Start preschools, and the findings were essentially the same as those with such schools included. That is, black children ( $54 \%$ of the reduced sample, $n=166$ ) had higher MVPA and VPA levels than did white children, and the preschools accounted for the largest proportion of the variance.

\section{CONCLUSIONS}

Accelerometry was used to measure the physical activity levels of children attending preschools. It was found that, on average, children participated in $\sim 7$ minutes of MVPA per hour of attendance at the preschool. Physical activity levels were significantly higher for boys than for girls, and black children were more active than white children. Activity levels of children were highly variable among schools, with averages ranging from 4.4 to 10.2 minutes of MVPA per hour among the 9 schools in which children were observed. The preschool that each child attended accounted for a sizeable fraction of the variance in child physical activity, which suggests that policies and practices of preschools have an important influence on the overall activity levels of the children the schools serve. Future research should examine the impact of specific school policies and practices on physical activity levels of preschool students, and subsequent policy intervention studies should test the effectiveness of specific preschool policies on physical activity and weight status among young children.

\section{ACKNOWLEDGMENTS}

This research was supported by a grant from the Gerber Products Company.

We thank John Sirard, PhD, for administering the study, Gaye 
Groover Christmus, MPH, for editing the manuscript, and Rebecca Polizzotto and Angela Lambert for collecting the data. We also appreciate the cooperation of the preschool directors and parents who participated in the study.

\section{REFERENCES}

1. Troiano RP, Flegal KM. Overweight children and adolescents: description, epidemiology, and demographics. Pediatrics. 1998;101:497-504

2. Strauss RS, Pollack HA. Epidemic increase in childhood overweight, 1986-1998. JAMA. 2001;286:2845-2848

3. Ogden CL, Troiano RP, Briefel RR, Kuczmarski RJ, Flegal KM, Johnson CL. Prevalence of overweight among preschool children in the United States, 1971 through 1994. Pediatrics. 1997;99(4). Available at: www.pediatrics.org/cgi/content/full/99/4/e1

4. Ogden CL, Flegal KM, Carroll MD, Johnson CL. Prevalence and trends in overweight among US children and adolescents, 1999-2000. JAMA. 2002;288:1728-1732

5. Freedman DS, Khan LK, Dietz WH, Srinivasan SR, Berenson GS. Relationship of childhood obesity to coronary heart disease risk factors in adulthood: the Bogalusa Heart Study. Pediatrics. 2001;108:712-718

6. Must A, Strauss RS. Risks and consequences of childhood and adolescent obesity. Int J Obes. 1999;23(suppl 2):S2-S11

7. Must A, Spadano J, Coakley EH, Field A, Colditz G, Dietz WH. The disease burden associated with overweight and obesity. JAMA. 1999; 282:1523-1529

8. Guo SS, Wu W, Chumlea WC, Roche AF. Predicting overweight and obesity in adulthood from body mass index values in childhood and adolescence. Am J Clin Nutr. 2002;76:653-658

9. United States Department of Health and Human Services. Healthy People 2010. 2nd ed. Washington, DC: Government Printing Office; 2000

10. United States Department of Health and Human Services. Physical Activity and Health: A Report of the Surgeon General. Atlanta, GA: Centers for Disease Control and Prevention; 1996

11. National Center for Chronic Disease Prevention and Health Promotion, Centers for Disease Control and Prevention. Guidelines for school and community programs to promote lifelong physical activity among young people. I Sch Health. 1997;67:202-219

12. National Association for Sport and Physical Education. Active Start: A Statement of Physical Activity Guidelines for Children Birth to Five Years. Reston, VA: National Association for Sport and Physical Education Publications; 2002

13. Federal Interagency Forum on Child and Family Statistics. America's Children: Key National Indicators of Well-Being. Washington, DC: US Government Printing Office; 2001

14. Finn KJ, Specker B. Comparison of Actiwatch activity monitor and Children's Activity Rating Scale in children. Med Sci Sports Exerc. 2000; 32:1794-1797

15. Reilly JJ, Coyle J, Kelly L, Burke G, Grant S, Paton JY. An objective method for measurement of sedentary behavior in 3- to 4-year olds. Obes Res. 2003;11:1155-1158
16. Sirard JS, Trost SG, Dowda M, Pate RR. Calibration of the Computer Science and Applications, Inc., physical activity monitor in preschool children [abstract]. Med Sci Sports Exerc. 2001;5(suppl):S144

17. DuRant RH, Baranowski T, Puhl J, et al. Evaluation of the Children's Activity Rating Scale (CARS) in young children. Med Sci Sports Exerc. 1993;25:1415-1421

18. Littell RC, Milliken GA, Stroup WW, Wolfinger RD. SAS System for Mixed Models. Cary, NC: SAS Institute; 1996

19. Finn K, Johannsen N, Specker B. Factors associated with physical activity in preschool children. J Pediatr. 2002;140:81-85

20. McKenzie TL, Sallis JF, Elder JP, et al. Physical activity levels and prompts in young children at recess: a two-year study of a bi-ethnic sample. Res Q Exerc Sport. 1997;68:195-202

21. Jackson DM, Reilly JJ, Kelly LA, Montgomery C, Grant S, Paton JY. Objectively measured physical activity in a representative sample of 3to 4-year-old children. Obes Res. 2003;11:420-425

22. McKenzie TL, Sallis JF, Nader PR, Broyles SL, Nelson JA. Anglo- and Mexican-American preschoolers at home and at recess: activity patterns and environmental influences. J Dev Behav Pediatr. 1992;13:173-180

23. Baranowski T, Thompson WO, DuRant RH, Baranowski J, Puhl J. Observations on physical activity in physical locations: age, gender, ethnicity, and month effects. Res Q Exerc Sport. 1993;64:127-133

24. Eaton WO, Ennis LR. Sex differences in human motor activity level. Psychol Bull. 1986;100:19-28

25. Thomas JR, Thomas KT. Development of gender differences in physical activity. Quest. 1988;40:219-229

26. Payne G, Isaacs L. Human Motor Development: A Lifespan Approach. 5th ed. Boston, MA: McGraw Hill; 2002

27. Hoffmann JP, Powlishta KK. Gender segregation in childhood: a test of the interactional style theory. J Genet Psychol. 2001;162:298-313

28. DiPietro JA. Rough and tumble play: a function of gender. Dev Psychol. 1981;17:50-58

29. Ward DS, Trost SG, Felton GM, et al. Physical activity and physical fitness in African-American girls with and without obesity. Obes Res. 1997;5:572-577

30. Taylor WC, Baranowski T, Young DR. Physical activity interventions in low-income, ethnic minority, and populations with disability. Am J Prev Med. 1998:15:334-343

31. Sallis JF, Prochaska JJ, Taylor WC. A review of correlates of physical activity of children and adolescents. Med Sci Sports Exerc. 2000;32: 963-975

32. Simons-Morton BG, McKenzie TJ, Stone E, et al. Physical activity in a multiethnic population of third graders in four states. Am J Public Health. 1997:87:45-50

33. Sallis JF, Zakarian JM, Hovell MF, Hofstetter CR. Ethnic, socioeconomic, and sex differences in physical activity among adolescents. I Clin Epidemiol. 1996;49:125-134

34. Kimm SY, Glynn NW, Kriska AM, et al. Decline in physical activity in black girls and white girls during adolescence. N Engl J Med. 2002;347: $709-715$

\section{ATTENTION ALL ADOLESCENT BOYS}

"The medical profession has subscribed to many passing fashions: from appendectomy, autointoxication, and pink disease to ptosis, bizarre surgical technologies, thalidomide, and the ills of masturbation. Incidentally, . . . the latter fashion has gone the full circle; a recent epidemiological triumph suggests that frequent masturbation in adolescence protects old gentlemen from prostate cancer (now they tell us)."

Weatherall D, review of Dally A. The Trouble With Doctors. London, United Kingdom: Robson; 2003

Submitted by Student 


\section{Physical Activity Among Children Attending Preschools}

Russell R. Pate, Karin A. Pfeiffer, Stewart G. Trost, Paula Ziegler and Marsha Dowda Pediatrics 2004; $114 ; 1258$

DOI: $10.1542 /$ peds.2003-1088-L

\begin{tabular}{|ll} 
Updated Information \& & including high resolution figures, can be found at: \\
Services & http://pediatrics.aappublications.org/content/114/5/1258 \\
References & This article cites 27 articles, 2 of which you can access for free at: \\
http://pediatrics.aappublications.org/content/114/5/1258\#BIBL & This article, along with others on similar topics, appears in the \\
following collection(s): & $\begin{array}{l}\text { School Health } \\
\text { http://www.aappublications.org/cgi/collection/school_health_sub } \\
\text { Sports Medicine/Physical Fitness } \\
\text { http://www.aappublications.org/cgi/collection/sports_medicine:physi } \\
\text { cal_fitness_sub }\end{array}$ \\
& $\begin{array}{l}\text { Information about reproducing this article in parts (figures, tables) or } \\
\text { in its entirety can be found online at: } \\
\text { http://www.aappublications.org/site/misc/Permissions.xhtml }\end{array}$ \\
Permissions \& Licensing & Information about ordering reprints can be found online: \\
http://www.aappublications.org/site/misc/reprints.xhtml
\end{tabular}




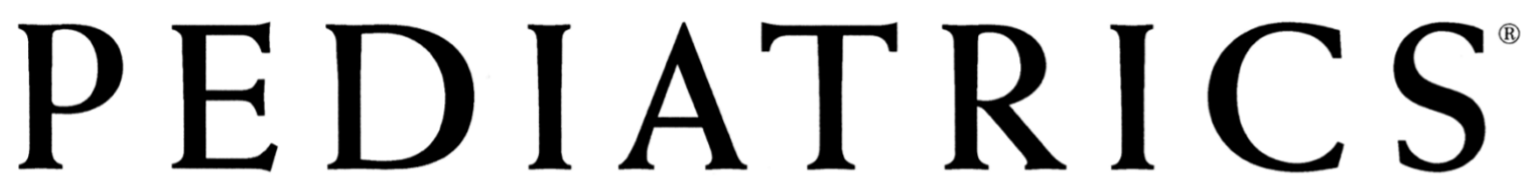

OFFICIAL JOURNAL OF THE AMERICAN ACADEMY OF PEDIATRICS

Physical Activity Among Children Attending Preschools

Russell R. Pate, Karin A. Pfeiffer, Stewart G. Trost, Paula Ziegler and Marsha Dowda Pediatrics 2004;114;1258

DOI: $10.1542 /$ peds.2003-1088-L

The online version of this article, along with updated information and services, is located on the World Wide Web at:

http://pediatrics.aappublications.org/content/114/5/1258

Pediatrics is the official journal of the American Academy of Pediatrics. A monthly publication, it has been published continuously since 1948. Pediatrics is owned, published, and trademarked by the American Academy of Pediatrics, 141 Northwest Point Boulevard, Elk Grove Village, Illinois, 60007. Copyright $\odot 2004$ by the American Academy of Pediatrics. All rights reserved. Print ISSN: 1073-0397. 